\title{
Parkinsonism secondary to duloxetine use: a case report
}

\author{
Arzu Bayrak, Bugra Cetin, Handan Meteris, Sermin Kesebir \\ Department of Psychiatry, Erenkoy Training and Research Hospital for Psychiatric and Neurological Diseases, Istanbul, Turkey
}

\begin{abstract}
In literature, there are more than hundred cases of extrapyramidal symptoms (EPS) associated with selective serotonin reuptake intibitors (SSRI) whereas EPS case reports associated with serotonin noradrenaline reuptake inhibitors (SNRI) are in a relatively small number. A SNRI group drug duloxetine that is used for indication of major depression since 2004 is a double acting antidepressant that acts by blocking serotonin and noradrenaline reuptake. Side effects of duloxetine on extrapyramidal system are not expected due to low affinity to D2 receptors. In this case, report manifestations of parkinsonism developed in a patient who used duloxetine for major depression are presented. Since any duloxetine induced EPS case has not reported so far, we have thought that this case can contribute to the literature.
\end{abstract}

Keywords: Duloxetine; extrapyramidal symptoms; parkinsonism.

$\mathrm{D}$ epression therapy can be defined as a process that was started with tricyclic antidepressants (TCA) and goes on with many kind of antidepressants like SSRIs, SNRIs and it continuously renews itself. It has been relatively 23 years since first antidepressant fluoxetine from SSRI group was started to be used in the treatment of depression [1]. Meanwhile, SSRI group are used widely so that side effects of this group of drugs have been oberved. These side effects include nausea, diarrhea and gastric irritation when the SSRIs were taken on an empty stomach due to their effects on gastrointestinal system, sexual dysfunction due to inhibition of serotonin reuptake and headache, vertigo, weight gain and weight loss during the early period of treatment. Also insomnia, irritability, agitation, tremor and extrapyramidal system symptoms are observed due to SSRI's effects on central nervous system [2]. Their extrapyramidal system symptoms can be sorted in decreasing order of frequency as akathisia, dystonia, parkinsonism and tardive dystonia [3]. Side effects of drugs on extrapyramidal system are rare relative to other side effects [4].

In some studies, drugs in the SNRI group were found to be more effective than those in the SSRI group [5]. An SNRI group drug duloxetine that is used for the indication of major depression since 2004 is a double acting antidepressant that acts as serotonin and noradrenaline inhibitor $[1,6]$. It inhibits dopamine reabsorption weakly and has a low affinity to histamine 1 , alfa 1 , beta $1,5 \mathrm{HT} 1$, cholinergic, histaminergic, D2, opioid and glutama- 
tergic receptors [6]. SNRI group drugs have similar side effects with drugs in the SSRI group. Minimal increase in heart rate, increase in blood pressure, nausea, vomiting, tiredness, somnolence or insomnia, headache, vertigo, sweating and dry mouth have been reported as side effects of duloxetine due to inhibition of noradrenaline reuptake [6]. Side effects on extrapyramidal system are not expected due to low affinity to $\mathrm{D} 2$ receptors.

In the literature, there are more than a hundred cases of EPS associated with SSRIs whereas case reports concerning EPS induced by SNRIs are in a relatively small number [3]. There is not any case report of parkinsonism associated with venlafaxine. However, three cases of akathisia has been reported with venlafaxine $[7,8,9]$.

One case that developed dyskinesia with duloxetine is reported [10].

In a review of duloxetine induced 59 cases with EPS, extrapyramidal symptoms including tremor (34\%), akathisia (14\%), dyskinesia (13\%), tardive dystonia and dystonia (8\%) were detected in respective percentage of patients [11].

There are two cases of milnacipran induced parkinsonism $[12,13]$.

In this case report, a patient using duloxetine for major depression who developed parkinsonism symptoms was presented. Since any duloxetine induced EPS case has not been reported before, this case can contribute to the literature.

\section{CASE REPORT}

S. A. was a 45-year- old, secondary school graduate, married housewife. She was admitted to outpatient service with complaints of social isolation, insomnia, reluctance and occasional cryings that started one year ago with increasing frequency. Her complaints intensified with her daughter's marriage which happened 6 months previously. She attempted suicide for 4 times within the last four months and she was complaining basically about the problems in her family. She did not receive regular treatment in the past and she had not suffered from a medical illness in the past.

In the psychiatric assessment, she was appearing at her chronological age. Her psychomotor activity was normal and she had depressed mood and affect. Any psychotic symptom was not detected. Deficiency in her voluntary and involuntary attention was observed. She was entertaining suicidal thoughts. Her judgement and insight were intact.

After anamnesis and psychiatric assessment, depression and cluster B personality disorder were diagnosed and the patient was admitted to mood disorder clinic. Olanzapine (10 mg $1 \times 1)$ and mirtazapine $(30 \mathrm{mg} 1 \mathrm{x} 1)$ treatment was started. With this treatment partial remission was obtained. Any side effects were not observed. After 23 days of hospitalization she was discharged to be followed up on an ambulatory basis. After 15 days in the outpatient clinic, based on her anamnesis, her symptoms of reluctance, social isolation, cries and anhedonia aggravated. Duloxetine $60 \mathrm{mg} /$ day was added to the treatment. In this examination, she did not define any physical complaint. Fifteen days later, in the second visit, she was having difficulty in walking with rigidity, restlessness and tremor in her hands. In the examination, cogwheel rigidity, increase in muscle tone, bradikynesia, rigidity and tremor at rest were determined. Patient's symptoms could not be explained with the use of any drug other than duloxetine. Duloxetine and the other drugs were ceased due to patient's disturbance and then biperiden ( 2 mg bid) treatment was started. At the third visit 15 days later her complaints decreased markedly. At the following visits biperiden treatment was ceased and any extrapyramidal system symptoms were not seen. Cranial MR imaging was not remarkable.

\section{DISCUSSION}

Pathophysiology of parkinsonism resulting from SSRI and SNRI group drugs is still not clearly understood. It is reported that it can be derived from the interaction between serotonin and norepinephrine in the cortex and basal ganglia and might be related with dopamine function [4]. The inhibitory effect of increase in serotonin transmission on dopamine pathway is another proposed [14].

It has been suggested that drugs may cause EPS with a change in postsynaptic transmission of dopamine receptors resulting in pathophysiological changes in basal ganglions [15].

Another proposed vision of developing parkinsonism with drugs is that it might be associated 
with a predisposition to Parkinson's disease [16].

Drug interactions are another mechanism that is related with the etiology of EPS associated with SSRIs and SNRIs. Duloxetine is metabolized by the enzymes cytochrome 1A2 and 2D6 and especially inhibition of CYP 1A2 increases duloxetine level markedly. Duloxetine causes drug interactions by inhibiting the enzymes CYP $1 \mathrm{~A} 2$ mildly and CYP 2D6 moderately [17]. In our case, the patient was receiving duloxetine and olanzapine. Olanzapine is the molecule that is, metabolized mostly by CYP 1A2 and then by CYP 2D6 [18] . Due to mild inhibition of CYP $1 \mathrm{~A} 2$ by duloxetine, we think that EPS in our patient is not related with the drug interactions but with the molecule itself. Although case reports of EPS secondary to duloxetine are rare, according to FDA Adverse Event Reporting System (AERS) incidence of EPS induced by duloxetine is higher than that induced by sertraline, escitalopram, fluoxetine and bupropion [11].

When we have reviewed the cases of EPS caused by antidepressants, we have seen that EPS were observed more often when there were predisposing factors such as psychomotor disorder, extrapyramidal symptoms that developed secondary to another drug use in the past, different kinds of drug applications at the same time, insufficiency of cytochrome enzymes, simultaneous Parkinson's disease, recent cessation of monoamine oxidase inhibitors [19]. Some studies have demonstrated that the presence of A1 allele in the polymorphism of D2 dopamine receptor gene taq 1a is a risk factor for EPS [20]. Ageing and female sex are also risk factors for antidepressant- induced EPS [11]. No family history for Parkinson's disease, simultaneous onset of movement disorder and duloxetine treatment did not provide supportive evidence about drug induced parkinsonism in this 45-year-old women.

In cases of antidepressant induced EPS, dose of drug can be reduced or it can be ceased or replaced by another antidepressant [3]. In some cases, underlying concealed Parkinson's disease can emerge by using antidepressants. At that time, levodopa can be added to treatment [12]. In our case, EPS emerged by adding duloxetine to the patient's current antipsychotic treatment and due to her complaints' severity treatment was ceased. Then biperiden ( $4 \mathrm{mg}$ / day) was started. After her complaints disappeared another antidepressant ie.fluoxetine is started.

Recently SNRIs are being used commonly just like SSRIs. It should be remembered that antidepressant associated EPS can occur at any time of the treatment. Monitorization of these side effects are important for both clinicians and patients.

Conflict of Interest: No conflict of interest was declared by the authors.

Financial Disclosure: The authors declared that this study has received no financial support.

\section{REFERENCES}

1. Schatzberg AF, Cole JO, DeBattista C. Klinik Psikofarmakoloji. Bozkurt A (Çeviri editörü) 6. Baskı, Ankara: Ayrıntı Basımevi 2010:35-157.

2. Hariri AG, Ceylan ME. Depresyonda İlaç Tedavisi:Özgül Serotonin Gerialım Engelleyicileri. Duygudurum Dizisi 2003;7:339_ 45.

3. Gerber PE, Lynd LD. Selective serotonin-reuptake inhibitor-induced movement disorders. Ann Pharmacother 1998;32:692-8.

4. Gill HS, DeVane CL, Risch SC. Extrapyramidal symptoms associated with cyclic antidepressant treatment: a review of the literature and consolidating hypotheses. J Clin Psychopharmacol 1997;17:377-89.

5. Papakostas GI, Thase ME, Fava M, Nelson JC, Shelton RC. Are antidepressant drugs that combine serotonergic and noradrenergic mechanisms of action more effective than the selective serotonin reuptake inhibitors in treating major depressive disorder? A meta-analysis of studies of newer agents. Biol Psychiatry 2007;62:1217-27.

6. Yüksel N. Duloksetin: Farmakolojisi. Klinik Psikiyatri 2009;12(Ek 1):3-8.

7. $\mathrm{Ng}$ J, Sansone RA, McDonald S. Akathisia and abnormal movements of the upper extremities with venlafaxine and methimazole. Gen Hosp Psychiatry 2009;31:388-90.

8. George M, Campbell JJ 3RD. Venlafaxine causing akathisia: a case report. J Neuropsychiatry Clin Neurosci 2012;24:3-4.

9. Lai $\mathrm{CH}$. Venlafaxine-related akathisia side-effects and management in a depressed patient. Psychiatry Clin Neurosci 2013;67:127-8.

10. Deuschle M, Mase E, Zink M. Dyskinesia during treatment with duloxetine. Pharmacopsychiatry 2006;39:237-8.

11. Madhusoodanan S, Alexeenko L, Sanders R, Brenner R. Extrapyramidal symptoms associated with antidepressants--a review of the literature and an analysis of spontaneous reports. Ann Clin Psychiatry 2010;22:148-56.

12. Arai M. Parkinsonism associated with a serotonin and noradrenaline reuptake inhibitor, milnacipran. J Neurol Neurosurg Psychiatry 2003;74:137-8. 
13. Muraoka T, Oku E, Sugataka K, Yamada S. A case of severe parkinsonism associated with short-term treatment with milnacipran. Clin Neuropharmacol 2008;31:299-300.

14. Damsa C, Bumb A, Bianchi-Demicheli F, Vidailhet P, Sterck R, Andreoli A, et al. "Dopamine-dependent" side effects of selective serotonin reuptake inhibitors: a clinical review. J Clin Psychiatry 2004;65:1064-8.

15. Dixit S, Khan SA, Azad S. A Case of SSRI Induced Irreversible Parkinsonism. J Clin Diagn Res 2015;9:VD01-VD02.

16. Gönül AS, Aksu M.SSRI-induced parkinsonism may be an early sign of future Parkinson's disease. J Clin Psychiatry 1999;60:410.

17. Knadler MP, Lobo E, Chappell J, Bergstrom R. Duloxetine: clinical pharmacokinetics and drug interactions. Clin Pharmaco- kinet 2011;50:281-94

18. Urichuk L, Prior TI, Dursun S, Baker G. Metabolism of atypical antipsychotics: involvement of cytochrome p450 enzymes and relevance for drug-drug interactions. Curr Drug Metab 2008;9:410-8.

19. Lane RM. SSRI-induced extrapyramidal side-effects and akathisia: implications for treatment. J Psychopharmacol 1998;12:192214.

20. Hedenmalm K, Güzey C, Dahl ML, Yue QY, Spigset O. Risk factors for extrapyramidal symptoms during treatment with selective serotonin reuptake inhibitors, including cytochrome P-450 enzyme, and serotonin and dopamine transporter and receptor polymorphisms. J Clin Psychopharmacol 2006;26:192,7. 